\title{
Quality Assessment of Antibiotic Oral Drug Formulations Marketed In Katsina State, Nigeria
}

\author{
* Mukhtar Gambo Lawal1, Muhammad Dauda Mukhtar², Abdulkadir Magaji Magashi²
}

${ }^{1}$ Department of Microbiology, Umaru Musa Yar'adua University, P.M.B 2218 Katsina

2Microbiology Department, Bayero University, P. M. B. 3011, Kano, Nigeria

\begin{abstract}
A B S T R A C T
There are increasing reports on the high incidence of substandard drugs, especially in developing countries.Pharmaceutical products have been reported to contain either no, low, or excessive amounts of the active pharmaceutical ingredient (API). Inview of the above, 112 samples of six different antibiotic oral drug formulations were evaluated for chemical quality by assessing the presence and the percentage content of the stated active pharmaceutical ingredients using validated HPLC assay as described in the official monograph of the British and United Stated pharmacopoeia. The result indicates that 43 (38.4\%) had active ingredients outside the set pharmacopoeial limit and therefore were non-compliant to the BP and the USP specifications for percentage content. Ampiclox and Cotrimoxazole had the highest proportion of samples with active ingredient outside the pharmacopoeial limit, and in three samples (one Augmentin and two Ampiclox), no active ingredient was detected. The presence of API lower than the claimed content declared on the packaging was the primary cause of non-compliance. The potential implications of the use of substandard drugs are treatment failure and the development of drug-resistance.
\end{abstract}

Keywords: Antibiotics, chemical quality, API, substandard drugs, HPLC

A R T I C L E I N F O: Received 18 Sept. 2019; Review Completed 19 Nov. 2019; Accepted 20 Nov. 2019; Available online 15 Dec. 2019
Cite this article as:

\section{INTRODUCTION}

$\mathrm{T}$ There is reportedly a high incidence of the availability of substandard medicines in several developing countries ${ }^{1}$. Antibiotics and antimalarial drugs account for the majority of products that are most often reported as substandard/counterfeit in the developing countries $^{2}$. The quality of medicines available in some less developed countries is inadequate in terms of the content of active ingredient ${ }^{3}$. Pharmaceutical products have been reported to contain either no, low, or excessive amounts of the active ingredient. The most common type of substandard/counterfeit antimicrobial drugs are those that have reduced amount of active drug, and the majority of them are manufactured in Southeast Asia and Africa ${ }^{2}$.

Inadequate quality drug preparations such as those that contain low amount of API have low efficacy that may result in therapeutic failure and development of resistance. In such cases where the drugs contain excessive amounts of active ingredients, this could lead to adverse clinical events such as toxicity in patients and the implications are even more crucial for paediatric formulations ${ }^{1,4}$.In Nigeria, the National Agency for Food and Drug Administration and Control (NAFDAC) has identified various forms of fake/counterfeit and substandard drugs, which include drugs with no active ingredient(s) and those with insufficient active ingredients ${ }^{5}$.

Chemical assays are used for the identification and estimation of the level of active ingredients in pharmaceuticals ${ }^{6}$. Chemical assays include automated methods such as high-performance liquid chromatography (HPLC) and UV spectrophotometry ${ }^{7}$. HPLC is regarded as the gold standard for drug quality analysis as it offers 
accuracy, specificity, and precision in quantifying the amount of stated API detected or its absence ${ }^{8}$.

One of the essential quality indicators of a given drug preparation is its content of the active pharmaceutical ingredient (API), a drug can be judged to be of good quality if its API is within the specification of the set pharmacopoeial limits ${ }^{4}$.

For being one of the enlisted drugs by the WHO model list of essential medicines ${ }^{9}$, antibiotics such as amoxicillinclavulanic acid, ampiclox, ciprofloxacin, cotrimoxazole, and metronidazole remains one of the first choice antimicrobials for use in chemotherapy. They are one of the most versatile antibiotics in clinical practice in Nigeria, and for this reason, it becomes imperative to determine the quality of these products frequently administered to patients to ensure that they are safe and fit for their intended use.

\section{MATERIALS AND METHODS}

\section{Collection of samples}

A total of 112 samples of six different antibiotic oral drug formulations were collected from various drug outlets (Patent medicine stores and Hospital pharmacies) located within the state. Samples were purchased on sight and anonymously by adopting the method of ${ }^{10}$.

The samples comprised of Augmentin, ampiclox, amoxicillin, ciprofloxacin, cotrimoxazole, and metronidazole. The selection of the drugs for the study was based on their inclusion in the WHO model list of essential medicines. Information obtained from clinicians testifies that these drugs are one of the most commonly prescribed antibiotic medications in the study area. Additionally, the selection of these drugs was based on their high usage; they represent a large proportion of total drug usage in the study area.

\section{Evaluation of the Chemical Quality Using HPLC Assay}

Assay for the content of the stated active pharmaceutical ingredients (APIs) of the samples was carried out using official monograph outlined in the United States Pharmacopoeia ${ }^{11}$ and British Pharmacopoeia ${ }^{12}$.

The assay for each drug sample and its equivalent reference standard was carried out using an ELITE-Lachrom HPLC System consisting of Ultra-Violet visible Detector L-2420, Column oven L-2300, an autosampler/injector L-2200, and a pump L-2130. The ELITE-lacrom Computer data system software generated the visual view of the chromotogram/calibration curves of each compound.

Analysis was done in replicates and mean values were recorded as a characteristic of the active ingredient content of the sample. Peak responses of the samples were compared with that of the standard. Following analyses, the drug content was calculated as the percentage of the stated amount of Active Pharmaceutical Ingredient and compared with pharmacopoeial limits specified in the BP ${ }^{12}$ and USP $41 \mathrm{NF}$ $36^{11}$.The chromatographic conditions employed for the assay of the different API such as column temperature, the stationary phase, mobile phase, amount of samples injected and the detection wavelength are presented in table 1.0.

Table 1.0: HPLC Conditions Employed for the Assay of the different APIs

\begin{tabular}{|c|c|c|c|c|c|c|c|}
\hline \multirow[b]{2}{*}{ API } & \multirow[b]{2}{*}{ Dosage Forms } & \multicolumn{6}{|c|}{ HPLC Conditions } \\
\hline & & Column & Mobile phase & $\begin{array}{l}\text { Column } \\
\text { temp. }\end{array}$ & $\begin{array}{l}\text { Injection } \\
\text { vol. }\end{array}$ & Flow rate & Wavelength \\
\hline Amoxycillin & $\begin{array}{l}\text { Capsules and } \\
\text { Suspension }\end{array}$ & $\begin{array}{l}4-\mathrm{mm} \times 25- \\
\mathrm{cm} ; 10-\mu \mathrm{m}\end{array}$ & $\begin{array}{l}\text { Acetonitrile \& Buffer } \\
(1: 24)\end{array}$ & & $10 \mathrm{ml}$ & $1.5 \mathrm{~mL} / \mathrm{min}$ & $230 \mathrm{~nm}$ \\
\hline $\begin{array}{l}\text { Amoxicillin and } \\
\text { Clavulanic acid }\end{array}$ & $\begin{array}{l}\text { Tablets and Oral } \\
\text { suspension }\end{array}$ & $\begin{array}{l}4 \mathrm{~mm} \times 30- \\
\mathrm{cm} ; 3-10-\mu \mathrm{m}\end{array}$ & $\begin{array}{l}\text { Methanol \& and } \\
\text { Buffer } \mathrm{NaPO}_{4}(1.19)\end{array}$ & & $20 \mathrm{ml}$ & $2 \mathrm{~mL} / \mathrm{min}$ & $220 \mathrm{~nm}$ \\
\hline Metronidazole/ & Tablets & $\begin{array}{l}4.6-\mathrm{mm} \times 15- \\
\mathrm{cm}\end{array}$ & $\begin{array}{l}\text { Methonol\& water } \\
(20: 80)\end{array}$ & & $10 \mu \mathrm{L}$ & $1 \mathrm{~mL} / \mathrm{min}$ & $254 \mathrm{~nm}$ \\
\hline $\begin{array}{l}\text { Metronidazole } \\
\text { benzoate }\end{array}$ & Oral suspension & $\begin{array}{l}4.6-\mathrm{mm} \times 15- \\
\mathrm{cm} ; 5 \mu \mathrm{m}\end{array}$ & $\begin{array}{l}\text { Acetonitile\& Acetic } \\
\text { acid (40:60) }\end{array}$ & $30^{\circ} \mathrm{C}$ & $5 \mathrm{ml}$ & $1.0 \mathrm{~mL} / \mathrm{min}$ & $316 \mathrm{~nm}$ \\
\hline Cloxacillin & $\begin{array}{l}\text { Capsules and } \\
\text { oral suspensions }\end{array}$ & $\begin{array}{l}4.6-\mathrm{mm} \times 25- \\
\mathrm{cm}\end{array}$ & $\begin{array}{l}\text { Acetonitrile \& buffer } \\
\mathrm{K}_{2} \mathrm{PO}_{4}(20: 80)\end{array}$ & & $20 \mu \mathrm{L}$ & $1.0 \mathrm{~mL} / \mathrm{min}$ & $225 \mathrm{~nm}$ \\
\hline Ampicillin & Capsules & $\begin{array}{l}25 \mathrm{~cm} \times 4.6 \mathrm{~mm} \\
5 \mu \mathrm{m}\end{array}$ & $\begin{array}{l}\text { Acetone \& } \\
\text { Ammonium acetate } \\
(10: 90)\end{array}$ & Ambient & $50 \mu \mathrm{L}$ & $1.0 \mathrm{~mL} / \mathrm{min}$ & $254 \mathrm{~nm}$ \\
\hline Ciprofloxacin & Tablets & $\begin{array}{l}4.6-\mathrm{mm} \times 25- \\
\mathrm{cm} ; 5 \mu \mathrm{m}\end{array}$ & $\begin{array}{l}\text { Acetonitrile \& } \\
\text { Phosphoric acid }\end{array}$ & $30^{\circ} \mathrm{C}$ & $10 \mu \mathrm{L}$ & $1.5 \mathrm{~mL} / \mathrm{min}$ & $280 \mathrm{~nm}$ \\
\hline $\begin{array}{l}\text { Sulfamethoxazole } \\
\& \text { Trimethoprim }\end{array}$ & $\begin{array}{l}\text { Oral suspension } \\
\& \text { Tablets }\end{array}$ & $\begin{array}{l}3.9-\mathrm{mm} \times 30- \\
\mathrm{cm}\end{array}$ & $\begin{array}{l}\text { Water, Acetonitrile } \\
\text { \&Triethylamine }\end{array}$ & & $20 \mu \mathrm{L}$ & $2.0 \mathrm{~mL} / \mathrm{min}$ & $254 \mathrm{~nm}$ \\
\hline
\end{tabular}




\section{RESULTS}

In general, a total of 112 of the sampled oral drug formulations were evaluated for chemical quality by assessing the presence and the percentage content of the active pharmaceutical ingredients using validated HPLC methods. Table 2.0 presents the proportion of sampled antibacterial oral drug formulations whose active ingredients are either within or outside the Pharmacopoeial limit as specified in the official monographs of the British and the
United States pharmacopeia. In all, $69(61.6 \%)$ of the samples studied contained amounts of active ingredient within the appropriate limits while $43(38.4 \%)$ had active ingredient outside the set pharmacopoeial limit and therefore were non-compliant to the BP (2017) and the USP (2018) specifications for percentage content. Ampiclox and Cotrimoxazole had the highest proportion of samples with active ingredient outside the pharmacopoeial limit, and in three samples (one Augmentin and two Ampiclox), no active ingredient was detected.

Table 2.0: Quality Assessment of the Sampled Antibiotic Oral Drug Formulations

\begin{tabular}{|l|l|l|l|}
\hline Type of formulation & No. of samples analyzed & $\begin{array}{l}\text { Number within the pharmacopoeial } \\
\text { limit (compliant) }\end{array}$ & $\begin{array}{l}\text { Number outside pharmacopoeial } \\
\text { limit (non-compliant) }\end{array}$ \\
\hline Augmentin & 13 & 09 & $04(30.8 \%)$ \\
\hline Amoxicillin & 34 & 21 & $13(38.2 \%)$ \\
\hline Ampiclox & 07 & 03 & $04(57.1 \%)$ \\
\hline Ciprofloxacin & 20 & 14 & $06(30.0 \%)$ \\
\hline Cotrimoxazole & 17 & 10 & $07(41.2 \%)$ \\
\hline Metronidazole & 21 & 13 & $08(38.1 \%)$ \\
\hline Total & $\mathbf{1 1 2}$ & $\mathbf{6 9}(\mathbf{6 1 . 6 \% )}$ & $\mathbf{4 3}(\mathbf{3 8 . 4 \% )}$ \\
\hline
\end{tabular}

The distribution of the sampled antibiotic oral drug formulations concerning country of origin shows that 82 (73.2\%) were locally made (made in Nigeria) while 30 (26.8\%) were foreign, most of which originated from India, China, Pakistan, and the United Kingdom.

Figure 1.0 shows the distribution and a comparative analysis of the quality of locally manufactured (made in Nigeria) samples of oral drug formulations versus their foreign counterparts. Of the overall $43(38.4 \%)$ of the sampled products that had API outside the set pharmacopoeial limit,

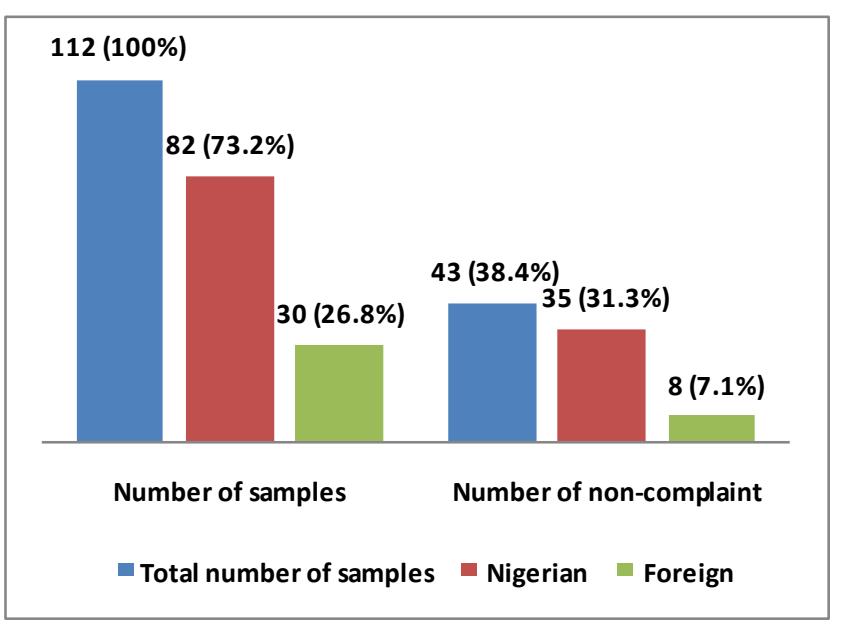

Figure 1: Distribution and the quality of locally manufactured (Nigerian) and foreign (imported) antibiotic products investigated. higher proportion of these were from the products manufactured in Nigeria,35(31.3\%) while only 08 (7.1\%) of the foreign antibiotic formulations had their API outside the set pharmacopoeial limit and therefore were non-compliant.

Of the 43 samples that were substandard concerning the content of API, $36(83.7 \%)$ had a low amount of active ingredient, while the presence of an excessive amount of API was observed in $04(9.3 \%)$. Additionally, in $03(7.0 \%)$ of the samples, no active ingredient was detected as present in figure 2.0.

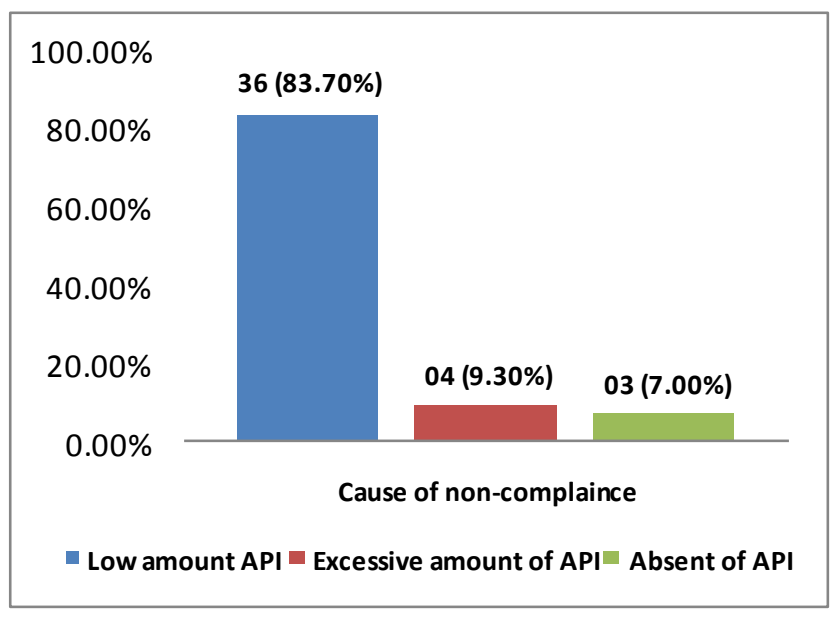

Figure 2: Present the cause of non-compliance to the pharmacopoeial limit among the substandard antibiotic oral drug formulations. 


\section{DISCUSSION}

In Nigeria and other parts of the world, there have been reports of the presence of active ingredients outside the pharmacopoeial limits $(1,2,10$, and 13). In this study, $38.4 \%$ of the sampled oral antibiotic formulations had active ingredients outside the set pharmacopoeial limit and therefore were non-compliant and substandard concerning pharmacopoeial standards.

The proportion of preparations failing to comply with pharmacopoeial standards in our study is comparable to the report of ${ }^{1}$. In their research on drug samples available from retail outlets in Nigeria and Thailand, $36.5 \%$ of the samples were substandard with respect to pharmacopoeial limits.

Higher incidences of substandard drugs with respect to the content of API have been reported. In a study on 581 samples of 27 different drugs from 35 pharmacies in Lagos and Abuja, Nigeria reported that 279 (48\%) samples did not comply with the set pharmacopoeial limits ${ }^{2}$. Similarly, a study on the quality assessment of some essential children's medicines sold in licensed outlets in the Ashanti Region, Ghana reported that $42(61.8 \%)$ failed the official drug content test ${ }^{14}$.

Five $(71.4 \%)$ of the seven samples of ampiclox capsules (ampicillin plus cloxacillin) were found to be of lower quality than the officially prescribed standards. Two (28.6\%) of the ampiclox capsules had no active ingredient. A lower incidence of $57.1 \%$ substandard ampicillin formulations were reported in Jos ${ }^{10}$, additionally, $60 \%$ of the samples of ampicillin capsules with low quality were reported 15 Likewise, in an in-vitro assessment of thirteen brands of $250 \mathrm{mg}$ ampicillin capsules available in Nigeria showed that $23.1 \%$ of the brands tested were substandard ${ }^{16}$. However, there was an improvement in the quality of oral ampicillin with regards to the content of the active ingredient that circulates in Kano. The active ingredient namely ampicillin trihydrate (BP), was observed to be present in all the samples analyzed, and all the samples had percentage ampicillin content in the region of $84-101 \%{ }^{17}$.

In our study, the prevalence of substandard products of amoxicillin brands $13 / 34(38.2 \%)$, is lower than the report of similar studies where $40 \%$ of Amoxicillin dry syrup and $25 \%$ capsules were substandard ${ }^{2}$. Similarly, $56 \%$ of amoxicillin capsules purchased from retail pharmacies within the Lebanese, Jordanian, Egyptian, and Saudi markets did not meet the United States Pharmacopeia (USP) requirements, and most had amounts bordering the lower limit ${ }^{18}$. However, all the samples of amoxicillin obtained from Ghana, Nigeria, and the United Kingdom complied with U.S. Pharmacopeia (USP) tolerance limits ${ }^{8}$.

Also, of the seventeen brands of Co-trimoxazole samples, seven $(41.2 \%)$ samples failed to comply with the BP and USP standard. Our observation here was that four of the Cotrimoxazole samples contained the right amount of sulfamethoxazole but had an amount of trimethoprim higher than the specified limit. Three samples, however, had both sulfamethoxazole and trimethoprim above the upper limit. Similar observations were reported in a study where $29.4 \%$ of the Co-trimoxazole samples were substandard with respect to pharmacopoeia1 limits (1). Another survey from Ghana reported that all the cotrimoxazole suspensions sampled failed the official drug content test ${ }^{14}$. Moreover, $60 \%$ of tablets of co-trimoxazole purchased in Ghana and Nigeria did not comply with U.S. Pharmacopeia (USP) tolerance limits ${ }^{8}$.

Moreover, $38.1 \%$ of the samples of metronidazole oral suspension and tablets failed the drug content assay. A report of a previous study has shown that all the metronidazole suspension $(100 \%)$ was unable to meet up with the pharmacopoeial specifications. In all the metronidazole suspensions, no active ingredient was detected ${ }^{2}$. However, one $(16.7 \%)$ of metronidazole samples studied in Ghana passed, and one failed marginally while three samples contained a much lower amount of the drug than the stipulated standard, as reported by ${ }^{14}$.

Nine of the thirteen brands of Augmentin (AmoxicillinClavulanic acid) samples had the right active ingredients, as indicated by the label claim. However, $30.8 \%$ of the samples were none compliant to the BP specification for percentage content. And in one brand of the Augmentin tablets, no active ingredient was detected. However, findings of a study from Lagos, Nigeria, indicate strongly that there was an improvement in the quality of amoxicillin-clavulanate potassium tablets with regards to the content of the active ingredient by ${ }^{19}$. Similarly, in a study to evaluate the pharmaceutical quality of tablets of Augmentin brands that are available in Libyan local market found that all the analyzed drugs attain standards of quality recommended by official compendia of the United States Pharmacopeia (USP), British Pharmacopeia (BP) and European Pharmacopoeia $(\text { Ph. Eur. })^{20}$.

As with other previous studies, the presence of the low amount of API was the cause for non-compliance observed in about $83.7 \%$ of the samples. In most cases, the concentration of the active ingredient is lower than the claimed content declared on the packaging. Reasons for the little amount of API observed in the samples may include poor manufacturing or transportation, decomposition, and poor storage conditions and dilution of drugs with other chemicals ${ }^{3}$.

The potential health implications from the use of substandard drugs are of great concern. Unfortunately, the administration of such drugs could result in serious health implications such as therapeutic failure, severe adverse drug reactions, increased morbidity and mortality, high cost of treatment, development of drug resistance, and waste of resources ${ }^{14,21}$. Where the amount of active drug is well below the stated amounts, the use of these preparations could result in serious under dosage leading to possible therapeutic failure and selection for drug-resistant organisms ${ }^{2}$.

Factors contributing to poor quality drugs in developing countries include absence of suitable manufacturing process and poor quality control, poor and uncontrolled storage conditions, such as high temperature and humidity conditions which could lead to decomposition of APIs in drugs as well as inadequate and ineffective regulations by government and its regulatory bodies significantly contribute to the increased 
prevalence of substandard and counterfeit medications in developing countries ${ }^{22}$.

\section{CONCLUSION}

The presence of API outside the set pharmacopoeial limit in $38.4 \%$ of the samples haves hown that a significant proportion of the oral antibiotic formulations available on sale during the study period are of poor quality. The finding of this study implies the possible therapeutic failure from the use of some oral drug formulations in the Nigerian drug market.

It is recommended that manufacturers of pharmaceutical antibiotic formulations should adhere tothe guidelines of current good manufacturing practices (CGMP) strictly at any stage of production as these may significantly affect the quality of the finished pharmaceutical products. They have to ensure the production of the right quality medicines that are safe, effective and potent.

On the other hand, NAFDAC and other regulatory agencies should carry out a more vigorous approach in monitoring programs and post-marketing surveillance towards ensuring the circulation of standard drugs in Nigeria.

\section{ACKNOWLEDGMENTS}

The authors appreciate the Management of Umaru Musa Yar'adua University Katsina and Tertiary Education Trust Funds, (TETFUND, Nigeria) for the research grant.

\section{CONFLICTS OF INTEREST}

The authors declare that they have no complicts of interests.

\section{REFERENCES}

1. Shakoor O, Taylor RB, Behrens RH. Assessment of the Incidence of Substandard Drugs in Developing Countries. Tropical Medicine and International Health. 1997; 2(9):839-845.

2. Taylor RB, Shakoor O, Behrens RH, Everard M, Low AS, Wangboonskul J, Reid RG, Kolawole JA. Pharmacopoeial quality of drugs supplied by Nigerian pharmacies. Lancet. 2001; 357:1933-1936.

3. Kelesidis T, and Falagas ME. Substandard/counterfeit antimicrobial drugs. Clinical Microbiology Review. 2015; 28(2):443-464.

4. Osei-Safo DHA, Egbo H, Nettey DY, Konadu and I. Addae-Mensah. Evaluation of the Quality of Some Antibiotics Distributed in Accra and Lagos. International Journal of Pharmaceutical Science and Research. 2016; 7(5):1991-2000.

5. Akunyili D, Counterfeit and Substandard Drugs, Nigeria's experience: Implications, Challenges, Actions, and Recommendations" Excerpts from the Meeting for Key Interest Groups on Health Organized by the World Bank in Washington D.C on $10^{\text {th }}-11^{\text {th }}$ March 2005.

6. Udobi Chinweizu Ejikeme and Onaolapo, Josiah Ademola. Comparison of Microbiological and Chemical Assay Methods used in the Quality Assessment of Ampicillin Suspensions Sold in Zaria-Nigeria. Nigerian Journal of Pharmaceutical and Applied Science Research. 2016; 5(1):6972
7. Nishant A. Dafale N, Uttam P. Semwal, Rupak K. Rajput, G.N. Singh. Selection of appropriate analytical tools to determine the potency and bioactivity of antibiotics and antibiotic resistance Journal of Pharmaceutical Analysis. 2016; (6):207-213

8. Fadeyi, Ifeyinwa, Mirza Lalani, Naiela Mailk, Albert Van Wyk, and Harparkash Kaur. Quality of the Antibiotics-Amoxicillin and CoTrimoxazole from Ghana, Nigeria, and the United Kingdom. American Journal of Tropical Medicine and Hygiene. 2015; 92(6):87-94.

9. World Health Organization. (2015). WHO Model Lists of Essential Medicines.

10. Kolawole JA, Olurunmi PO, Okeniyi SO, and Shawrpshaka YJ. Quality and Availability of Ampicillin Products in Jos, Nigeria. Nigerian Journal of Pharmacy. 2002; 33:27-42.

11. United States Pharmacopoeia (2018).National Formulary 36 (U.S.P. 41, N.F. 27) United States Pharmacopoeial Convention Inc., Rockville, MD.

12. British Pharmacopoeia (2017). The Stationery Office, London, pp.V396 -V402

13. Newton PN, Green MD, Fernandez FM, Day NPJ, White NJ. Counterfeit anti-infective drugs. Lancet Infectious Disease. 2006; 6: 602-613.

14. Grace Frimpong, KwabenaOfori-Kwakye, Noble Kuntworbe, Kwame OheneBuabeng, YaaAsantewaaOsei, Mariam El Boakye-Gyasi, and OfosuaAdi-Dako. Quality Assessment of Some Essential Children's Medicines Sold in Licensed Outlets in Ashanti Region, Ghana. Hindawi Journal of tropical medicine. 2018;

15. Okeke IN, and Lamikankra A. Quality and Bioavailability of Ampicillin Capsules Dispensed in a Nigerian Semi-urban Community. African Journal of Medicine and Medical Sciences. 2001; 30(1-2):47-51.

16. Iwuagwu MA, and Onyeonwu N. In Vitro Assessment of Ampicillin Capsules Marketed in Nigeria. International Journal of Pharmacy Practice. 1992; 3(1):169-171.

17. Mukhtar MD, Maryam IA, and Adoum AO. Quality Assessment of Some Brands of Ampicillin Oral Formulations on Sale in Some Parts of Kano by Thin Layer Chromatography and Microbiological Techniques. Journal of Research in Biosciences. 2006; 2(1).

18. Kyriacos S, Mrouch M, Chachine RP, and Khouzam O. Quality of Amoxicillin Formulations in some Arab Countries. Journal of Clinical Pharmaceutical Therapy. 2008; 33(4): 375-379. DOI: 10.1111/j.13652710.2008.00926.x.

19. Olanrewaju Odulaja J, Azubuike C. Paul1, and Akinleye M. Olusola. Quality assessment of amoxicillin-clavulanate potassium tablets in Lagos, Nigeria. Journal of Chemical and Pharmaceutical Research. 2012; 4(12): 5032-5038

20. Mohamed N. El Attug, Amal Ammar, SeragTunsi, SohailElmjrab, Shukri Al-Sharif, Abdulmonem Gobassa, Emhemmed Elgallal. Pharmaceutical Evaluation of an Augmentin Brand Manufactured in Different Countries. American Journal of Pharmacy and Pharmacology. 2015; 2(4):35-44.

21. Henry Nettey, Grace Lovia Allotey-Babington, Philip Debrah, OfosuaAdi-Dako, Manal Shaick, Isaac Kintoh, Francis Arnansi, MakafuiNyagblordzro, Marvin Holison. The Quality and in Vitro Efficacy of Amoxicillin/Clavulanic Acid Formulations in the Central Region of Ghana. Pharmacology \& Pharmacy. 2014; 5:49-60.

22. Mweemba W. Evaluation of the quality of anti Tuberculosis drugs in Lusaka, Zambia. Medical Journal of Zambia. 2015; 42(4):144-149. 